\title{
Actividad antimicrobiana del Diaminofluoruro de Platay del Nitrato de Plata en cultivos de Streptococus mutans y Lactobacillus
}

\author{
Antimicrobial activity of Silver Diamino fluoride and Silver Nitrate in cultures of Streptococus mutans \\ and Lactobacillus
}

Zaida Moya-de-Calderón ${ }^{1}$, Alicia Huamán Morales ${ }^{1}$, Cleidy Zeballos Villalobos

\section{Sr. Editor:}

Los sellantes dentales se usan en la prevención y control de la caries dental (1). A pesar de las alternativas clínicas para aplicar sellantes preventivos de resinas fluidas sin relleno inorgánico o sellantes ionoméricos que intercambian los iones minerales entre el material y el diente (2); se continúa en la búsqueda de opciones preventivas o terapéuticas para la caries dental.

Los sellantes resinosos que se usan en forma convencional no tienen actividad bactericida y bacteriostática, situación que limita su acción terapéutica (3). Sin embargo, el diamino fluoruro de plata (DFP) y el nitrato de plata (NP) son descritos como potenciales sustancias con propiedades antimicrobianas. El DFP fue utilizado ampliamente como cariostático en décadas pasadas (4); sin embargo, su aplicación tuvo como efecto adverso la coloración negruzca del tejido dentario, incluso se consideró como una sustancia nociva para el tejido pulpar en lesiones cariosas avanzadas.

Actualmente se investiga la aplicación del DFP como sellante en primeros molares sanos. Creemos que por la ubicación anatómica de los dientes en la boca, no tiene efecto estético negativo, porque se aplica en piezas dentales que no son visibles durante el habla y en otras actividades diarias del paciente. Además, durante aplicación, el DFP está en contacto con molares sanos, sin afectar el tejido pulpar. El NP, es otra sustancia que tiene propiedades similares al DFP de menor costo y similar al DFP.

A pesar de lo comentado, no existe evidencia sobre la efectividad del DFP y el NP sobre Streptococcus mutans y Lactobacillus. Por esta razón, el objetivo del estudio fue evaluar el efecto bactericida y bacteriostático del DFP y del NP en diferentes concentraciones sobre las cepas bacterianas mencionadas (5).

Para esto, se realizó un estudio experimental, usando cultivos de cepas certificadas de Streptococcus mutans y Lactobacillus sp, que fueron obtenidas del laboratorio microbiológico kwik stik ${ }^{\mathrm{TM}}$. Se usó la presentación comercial del DFP al 30\% incorporada en discos de papel filtro que se aplicaron sobre los cultivos de Streptococcus mutans y Lactobacillus. El NP fue proporcionado por Laboratorio Khemia ${ }^{\circledR}$ (Brasil), diluido en concentraciones de 20\%, 25\%, 30 $\%, 35 \%$ y $40 \%$ fue aplicado en discos de papel filtro sobre los cultivos de Streptococcus mutans y en concentraciones de $35 \%, 40 \%$ y $44 \%$ sobre los cultivos de Lactobacillus.

En el experimento se realizaron 12 réplicas para cada cepa con el método Kirby-Bauer que consiste en la difusión disco placa, cada placa contenía las diferentes concentraciones del NP y la única concentración 
del DFP, luego cada disco de papel filtro fue colocado con una separación de no menos $24 \mathrm{~mm}$ entre sus centros y el halo de inhibición formado fue medido en mm. Los resultados se presentan como Media y Desviación Estándar X (DE) (tabla 1).

En la tabla 1, observamos que el DFP al $30 \%$ y el NP en diferentes concentraciones, tuvo efecto sobre las cepas bacterianas estudiadas, esto podría deberse a que dichas sustancias inhiben específicamente las proteínas que descomponen la matriz orgánica de la dentina expuesta: metaloproteinasas de la matriz (6); catepsinas (7); y bacterias colagenasas; además el DFP supera a otros agentes cariostáticos en el arresto de las bacterias cariogénicas a nivel de los túbulos dentinarios. (8) permiten proponer al DFP y al NP como la alternativa para los sellante en los dientes posteriores sanos.

La orientación clínica del presente trabajo propone la sustitución de los sellantes convencionales (material inerte de elevado costo), por el uso del DFP y del NP aplicado en primeros molares sanos, para los programas sociales preventivos de salud pública, por su bajo costo, sus propiedades bactericida y bacteriostática, útil especialmente en niños.

Conflicto de Interés: las autoras declaran no tener ninguna fuente potencial de interés.

Financiamiento: Autofinanciado.

Tabla 1. Resultados del estudio experimental

\begin{tabular}{lccc}
\hline \multicolumn{1}{c}{ Bacteria } & $\begin{array}{c}\text { Nitrato de } \\
\text { Plata en } \\
\text { concentraciones } \\
\text { X(DE) }\end{array}$ & DFP al 30\% & $\mathrm{p}^{*}$ \\
\hline $\begin{array}{l}\text { Streptococcus } \\
\text { mutans } \\
\text { Lactobacillus }\end{array}$ & $9,78(1,44)$ & $20,67(1,37)$ & \\
sp. & $7,6(2,72)$ & $16,75(3,11)$ & $<0,001$ \\
\hline
\end{tabular}

* El valor de p fue calculado con la prueba T de Student.

Un ensayo clinico demostró mayor efectividad del DFP al 25\% en comparación con el barniz de fluoruro de sodio al 5\%, para la detención de caries en 1070 niños de 3 a 4 años conducido durante 30 meses. (9) Otro ensayo clínico aleatorizado, considera como nueva propuesta un protocolo para el uso del DFP en la detención de las lesiones iniciales de caries proximales. Se aplicó el DFP en 504 superficies dentarias examinadas a los 6, 12 y 24 meses para evaluar la progresión de las lesiones cariosas mediante el examen visual y/o radiográfico. Los resultados preliminares evidencian la efectividad del DFP. (10)

Las propiedades del DFP sobre el Streptococcus mutans y Lactobacillus, (principales colonizadores de las fosas y fisuras de los primeros molares permanentes) y los ensayos clínicos discutidos en la presente carta,

\section{Correspondencia}

Zaida Moya-de-Calderón

Correo electrónico: zambpe@yahoo.com

\section{REFERENCIAS BIBLIOGRÁFICAS}

1. Ahovuo-Saloranta A, Forss H, Walsh T, et al. Sealants for preventing dental decay in the permanent teeth. Cochrane Database Syst Rev. 2013;(3):CD001830. doi: 10.1002/14651858.CD001830.pub4

2. Hilgert LA, Leal SC, Freire GML, Mulder J, Frencken JE. 3-year survival rates of retained composite resin and ART sealants using two assessment criteria. Braz oral. Res. 2017; 31:e35. doi: 10.1590/1807-3107BOR2017.vol31.0035

3. Yu F, Yu H, Lin P, et al. Effect of an Antibacterial Monomer on the Antibacterial Activity of a Pit-andFissure Sealant, PLoS One. 2016;11(9):e0162281. doi: 10.1371/journal.pone.0162281. 
4. Chu CH, Gao SS, Li SK, Wong MC, Lo EC. Effectiveness of dental caries arrest treatment in primary teeth using $\mathrm{AgNO} 3$ followed by $\mathrm{NaF}$ varnish. Washington DC: Clinical Trials.gov. 2016. (Citado el 15 de julio del 2020) Disponible en: https:// clinicaltrials.gov/ct2/show/NCT02019160

5. Cheng L. Limited evidence suggesting silver diamine fluoride may arrest dental caries in children. J Am Dent Assoc. 2017;148(2):120-122. doi: 10.1016/j. adaj.2016.11.022

6. Mei ML, Li QL, Chu CH, Yiu CKY, Lo ECM. The inhibitory effects of silver diamine fluoride at different concentrations on matrix metalloproteinases. Dental Materials. 2012;28(8):903-908. doi: 10.1016/j. dental.2012.04.011.

7. Mei ML, Ito L, Cao Y, Li QL, Chu CH, Lo ECM. The inhibitory effects of silver diamine fluorides on cysteine cathepsins. Journal of Dentistry. 2014;42(3):329335. doi: 10.1016/j.jdent.2013.11.018

8. Mattos-Silveira J, Flriano I, Ferreira F, et al. New proposal of silver diamine fluoride use in arresting approximal caries: study protocol for a randomized controlled trial. Trials. 2014;15:448. doi: 10.1186/1745-6215-15-448

9. Rosenblatt A, Stamford TCM, Niederman R. Silver diamine fluoride: a caries "silver-fluoride bullet". Journal of Dental Research. 2009; 88(2):116-125. doi: 10.1177/0022034508329406

10. Gao SS, Zhao IS. Clinical Trials of Silver Diamine Fluoride in Arresting Caries among Children. JDR Clin Trans Res. 2016;1(3):201-210. doi: $10.1177 / 2380084416661474$

Recibido: 13-12-19

Aceptado: $17-06-20$ 